\begin{tabular}{|l|r|}
\hline \multicolumn{1}{|c|}{ S sciendo } & \begin{tabular}{c} 
NCF $\begin{array}{l}\text { Nordic } \\
\text { Concrete } \\
\text { Federation }\end{array}$ \\
\hline $\begin{array}{l}\text { (C) Article authors. This is an open access article distributed under } \\
\text { the Creative Commons Attribution-NonCommercial-NoDerivs } \\
\text { licens. (http://creaticecommons.org/licenses/by.nc-nd/3.0/). }\end{array}$
\end{tabular} \\
\hline & $\begin{array}{r}\text { ISSN online 2545-2819 } \\
\text { ISSN print } \quad \text { 0800-6377 }\end{array}$ \\
DOI: $10.2478 /$ ncr-2019-0018 & Received: Oct. 5, 2019 \\
& Revision received: Dec. 3, 2019 \\
& Accepted: Dec. 4, 2019 \\
\hline
\end{tabular}

\title{
Effect on Radon Exhalation Rate Due to Cracks in Concrete
}

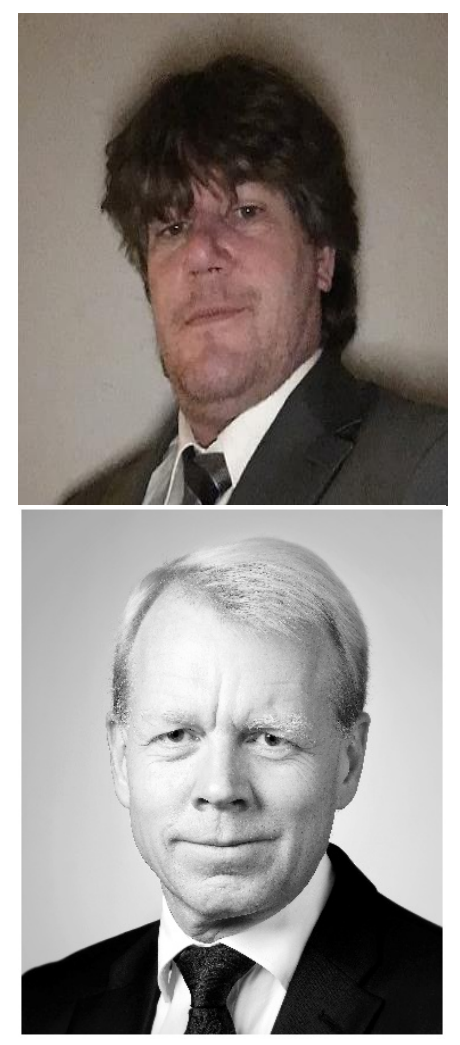

Magnus Döse

Doctoral candidate, KTH Royal Institute of Technology

Dept. of Civil and Architectural Engineering, Concrete Structures

The Swedish Research Institute (RISE CBI)

SE-501 15 Borås Sweden

Magnus.dose@ri.se

Johan Silfwerbrand

Professor, KTH Royal Institute of Technology

Dept. of Civil \& Architectural Engineering

Brinellvägen 23

SE-100 44 Stockholm, Sweden

jsilfwer@kth.se

\section{ABSTRACT}

The second largest cause of lung cancer in the World is related to radon $\left({ }^{222} \mathrm{Rn}\right)$ and its progenies in our environment. Building materials, such as concrete, contribute to the production of radon gas through the natural decay of ${ }^{238} \mathrm{U}$ from its constituents. The Swedish Cement and Concrete Research Institute (CBI), part of RISE (Research Institute of Sweden AB), has examined the effects of cracks in concrete on two different concrete recipes where an Ordinary Portland Cement, OPC-CEM-I concrete (REF) and an OPC concrete including a hydrophobic additive (ADD) were addressed. Two concrete prisms from each concrete recipe were examined. The radon exhalation rate was measured in the pristine state and after concrete cracks had been induced into the concrete prisms. Measurements were performed with an ATMOS 33 ionizing pulsation chamber. The results indicate a strong influence of cracks on the radon exhalation rate. An 
increase in radon exhalation rate was calculated for every test prism. The increase in radon exhalation rate varied between 80 and $260 \%$. The crack apertures may play a significant role on the exhalation rate. The concrete prisms with the largest apertures (ADD) also generated the highest radon exhalation rates. The results imply that there could be a substantial variation in the exhalation rate, due to numerous factors, but nonetheless, the results should, raise the awareness of the impact cracks in concrete structures, may have on the final exhalation rate of radon. The exhalation rate of the recipe with an additive (ADD) also showed a lower exhalation rate than for the reference recipe (REF), when compared in a pristine state. This was in part expected. However, the effect of induced cracks and its aperture, seemingly trumps the effect that an additive may play on the radon exhalation rate, when cracks are induced.

The hypothesis is in part verified in view of the results of the prism for the ordinary Portland recipe (REF-prisms), were an increase of approximately $100 \%$ would be expected due to the total surface increase. The results also indicate this. The major increase in the radon exhalation rate of the ordinary Portland recipe including an additive, implies however other factors, such as minor internal cracks, that may substantially contribute to the final exhalation rate.

Key words: Radon, concrete, cracks, radon exhalation rate, building materials.

1.

\section{INTRODUCTION AND BACKGROUND}

1.1

\section{Ionizing radiation and health}

The second largest cause of lung cancer is ionizing radiation generated by radon and its progenies [1]. Building materials, such as concrete, contribute to the production of radon gas through the natural decay of ${ }^{238} \mathrm{U}$ from its constituents. In Sweden mostly crushed bedrock is used for concrete production, nonetheless of particle size fraction.

The Swedish Cement and Concrete Research Institute (CBI), part of the Swedish Research Institute (RISE), has examined the influence of forced cracks on concrete prism's and the effect on the radon exhalation rate at an expected relative humidity of $60 \%$. The recipes contained identical aggregates and the water binder ratio $(\mathrm{w} / \mathrm{b})$ was set to 0.55 . In this study the concrete prisms investigated had firstly been measured in a pristine state. Thereafter the same prisms were exerted to a pressure press, where three cracks were produced in each concrete prism and thereafter measured once again.

Only very few studies have addressed the issue of cracks in concrete and the effect on the exhalation rate by inducing cracks into the concrete. Man \& Young [2] performed a study simulating cracks by shifting the surface area of concrete blocks but with an overall identical volume of the concrete cubes. There was no evidence of any difference in the exhalation rate. However, Landman [3] showed the effect of cracks in concrete by addressing the exhalation rate of a concrete slab resting on an underlying soil. The exhalation rate was modelled with an intact concrete slab and with a slab that had been induced with cracks. The effect of the cracks induced into the concrete showed a 20 -fold increase of the radon exhalation rate compared to a concrete slab without cracks. This effect, however, was mainly contributed to the underlying soil. A recent study by Ajayi et al. [4], with focus on radon generated in fractured rocks, imply that an increase in fracture density $\left(\mathrm{m} / \mathrm{m}^{2}\right)$ of $10 \%$ for a fractured rock may increase the radon flux (radon generated) by $15 \%$. The effect of fractures/cracks density consequently has a large impact on the radon exhalation rate. 


\section{$1.2 \quad$ Hypothesis}

Cracks in concrete structures are considered having a substantial effect on the radon exhalation rate. A visible crack means that new surface areas are open towards the surrounding air. The hypothesis is that the increase in radon exhalation rate is proportional to the magnification of the surface area against the surrounding air. A prerequisite is that the relative humidity is approximately equal throughout the concrete.

Figure 1 presents a schematic approach. The "initial surface" includes the top surface (A) marked by a light grey colour (red arrow). The total surface area includes the top surface area (initial surface area) and the black area that are exposed after cracks are initiated (A1). Of course, both surface areas along the crack are included in the calculations although the Figure only shows one side. Please note that all areas except the top surface are sealed.

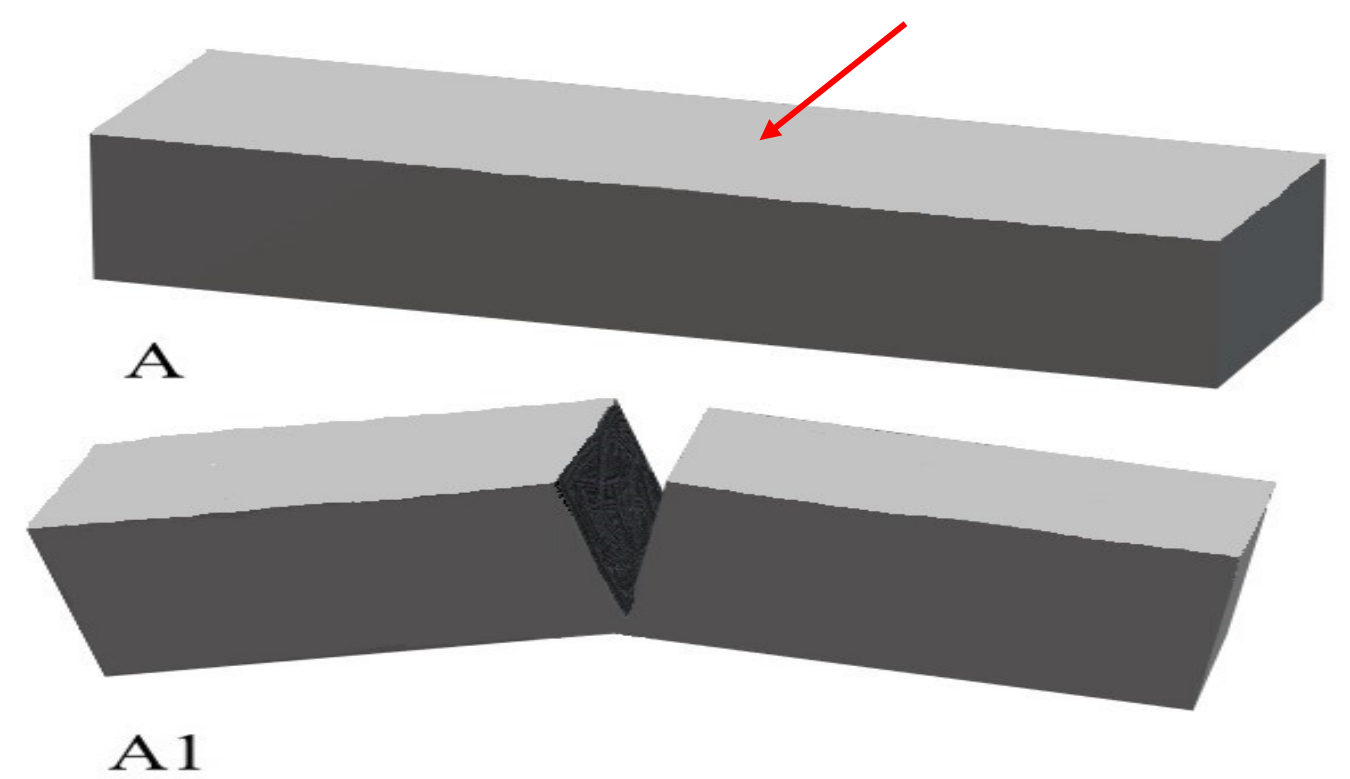

Figure 1 - A schematic approach to describe the hypothesis, where the "initial surface/top surface" area of the concrete prism in a pristine state (A) is shown (light grey area) and the concrete prism with the exposed surface area (black surface), when cracks are induced (A1) that are included in the calculations. 


\subsection{Concrete recipes}

Two different concrete recipes were chosen. One, with only ordinary Portland cement (OPC-CEM I), abbreviated "REF" and one including a bulk additive (bulk additive/liquid additive) abbreviated "ADD". The cause for including an additive was due to earlier investigations [6] that had shown that an addition of a liquid additive with hydrophobic character could lower the exhalation rate.

The concrete recipes contained identical constituents (aggregates, cement, water) where the only difference between the recipes was a contribution of a different additive for one recipe. For each concrete recipe, two concrete cubes $\left(100 \times 100 \times 100 \mathrm{~mm}=0.001 \mathrm{~m}^{3}\right)$ and two concrete prisms $\left(100 \times 100 \times 500 \mathrm{~mm}=0.005 \mathrm{~m}^{3}\right)$ were cast. The cast concrete was demoulded and cured in a water bath for one month to reduce and prevent cracking. A compressive strength test of the cubes was made after 28 days and when the radon exhalation measurements started. The radon exhalation measurements were initiated approximately 1 year after casting.

A standard CEM I 52.5 R (rapid hardening properties) from the Skövde cement factory was used as the reference binder. The air content was assumed to $\sim 1$ vol. $\%$. A cement-content of $350 \mathrm{~kg} / \mathrm{m}^{3}$ was applied. The additive was applied to $1 \%$ of the water content. The additive used originates from Wacker and is named Silres 1801. It is a liquid hydrophobic additive. To prevent complete cracking though the entire prism and to attain a possibly controlled procedure of inducing cracks, $30 \mathrm{~mm}$ steel fibres with open ends were used. Approximately $50 \mathrm{~kg} / \mathrm{m}^{3}$ were applied in each recipe. Table 1 presents the recipes of the concrete mixes.

Table 1 -Recipes, constituents and proportions of the assessed concrete prisms.

\begin{tabular}{ccccc}
\hline Constituents & \multicolumn{2}{c}{$\begin{array}{c}\text { Standard recipe } \\
\text { "REF" } \\
\text { Wg/m }\end{array}$} & $\begin{array}{c}\text { Standard recipe + additive } \\
\text { "ADD” }\end{array}$ \\
& 350.0 & 14.6 & 350.0 & 14.6 \\
Cement ${ }^{1}$, CEM I & 1357.0 & 56.5 & 1349.2 & 56.3 \\
Crushed aggregate, 0/6 (75 wt \%) & $\mathrm{kg} / \mathrm{m}^{3}$ & Weight (\%) \\
Crushed aggregate 8/16 (25 wt \%) & 452.3 & 18.8 & 449.7 & 18.8 \\
Fibre reinforcement & 50.2 & 2.1 & 49.9 & 2.1 \\
Water & 192.5 & 8 & 192.5 & 8 \\
Superplasticizer (sikament 56) & $\sim 0.7$ & - & -0.7 & - \\
Additive, Silres 1801 & - & & 3.5 & 0.1 \\
Total & 2402.3 & & 2395.0 & \\
w/c ratio & 0.55 & & 0.55 & \\
\hline
\end{tabular}

\footnotetext{
${ }^{1}$ The cement paste volume approximates $0.112 \mathrm{~m}^{3}$ per $\mathrm{m}^{3}$ of concrete
} 
The cast cubes and prisms were after one month of curing in water placed in plastic boxes that uses a closed system to enable a controlled environment. A circulation pump was connected by plastic pipes, $32 \mathrm{~mm}$ in diameter, to an inlet on top of the plastic boxes, were the air was circulated in a closed system to a ventilation fan on the side (Figure 2a) and transported via the $32 \mathrm{~mm}$ pipes back into the boxes on the far side of the plastic lids. The top of the plastic boxes had a lid with two black plastic tubes inserted into the lids and put in place by epoxy glue and thereafter sealed with aluminum tape (Figure $2 b$ ). The tubes were used as to measure the relative humidity of the air inside the boxes. Probes where inserted into the tubes and fixed in place at least 48 hours before a reading commenced.

The bottom of the plastic boxes had initially a 5-6 mm layer of $\mathrm{NaCl}$ salt resting on the bottom. The concrete cubes were put in place, resting on parallel wooden sticks, ca $15 \mathrm{~mm}$ in height, with the salt placed in between the sticks. The wooden sticks ensured that the salt is separated from the samples. The salt initially had a relative humidity of $75 \%$ at $23^{\circ} \mathrm{C}$. The use of the $\mathrm{NaCl}$ was envisaged promoting a slow hydration in order to hinder the development of any micro cracks.

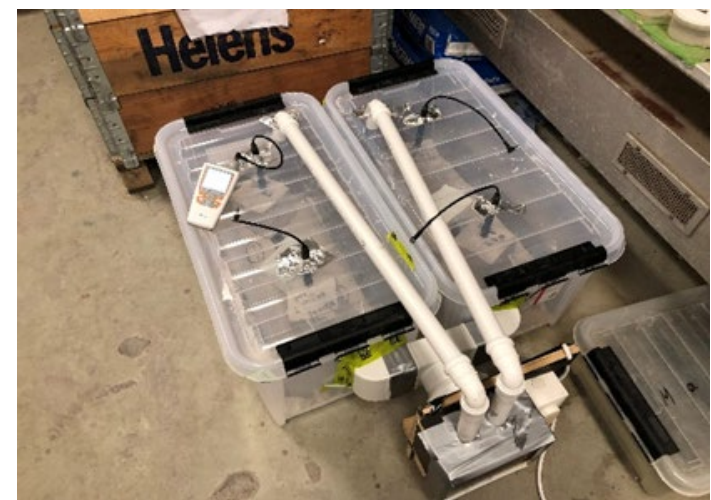

(a)

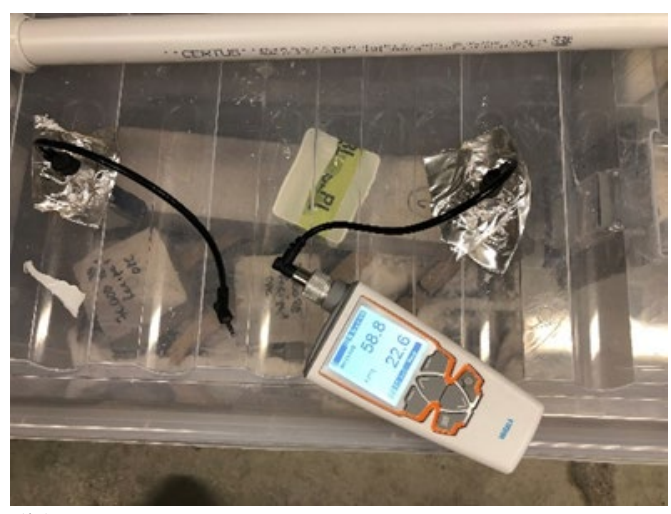

(b)

Figure 2 - (a) The closed system containing the cast prisms and cubes in a controlled environment where the air was re-circulated within the boxes by a fan. (b) Measurement of the relative humidity within the box. The reading is taken $5 \mathrm{~cm}$ below the top of the lid and shows $58.8 \%$ in $\mathrm{RH}$ at $22.6^{\circ} \mathrm{C}$.

The samples enclosed in the plastic boxes were stored in a conditioning room with $50 \% \mathrm{RH}$ and a temperature of $23^{\circ} \mathrm{C}$.

Weight measurements were conducted every 3-4 week. After approximately 4-5 months the salt was replaced by sodium bromide $(\mathrm{NaBr})$ with a relative humidity of $59,1 \%$ at $20^{\circ} \mathrm{C}$. An extra input of salt was also done after 6-7 months. The replacement of the salt $(\mathrm{NaCl}$ to $\mathrm{NaBr})$ was done in order to ensure a lower relative humidity of the concrete prisms. The cause relates to experiments by several authors (Cozmuta et al. [7]; Fournier et al. [8]; Döse [9]) that show that a difference of $\mathrm{RH}$ in the interval 60-70\% only will have a limited effect on the radon exhalation rate of the concrete. At higher or lower RH values the effect could be more pronounced.

At a weight difference $<1$ gram per week it was decided to initiate the measurements, meaning, after the prisms had been monitored for approximately a year the first concrete prism was taken out. Figure 3 presents the weight differences of each concrete prism per week. Note the effect of shifting salt at 4-5 months and 6-7 months. 


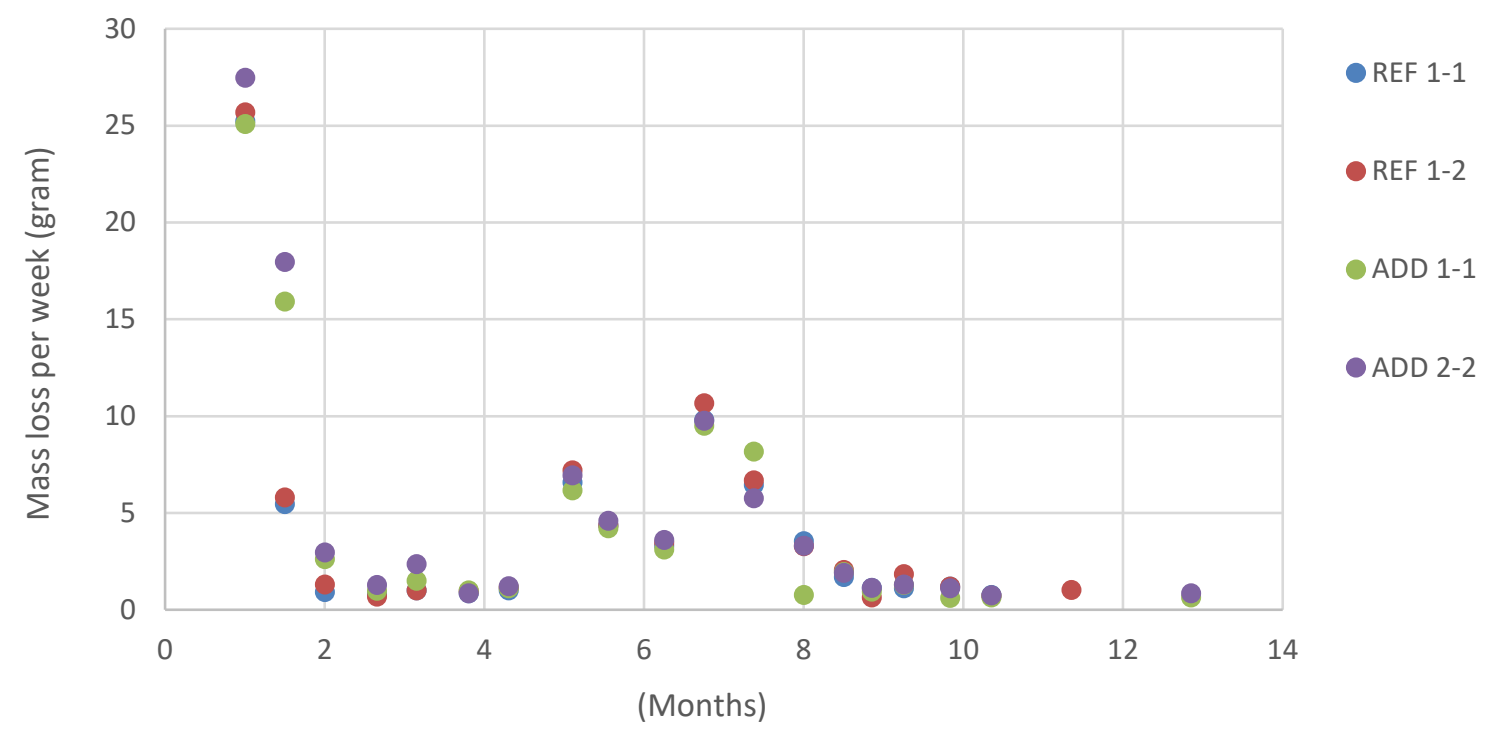

Figure 3 - Weight difference per week (grams) as a function of time for each concrete prism investigated.

The theoretical approach contained measurements of each prisms in its pristine state and thereafter each prism was exerted to a pressure press (Figure 4a) where induced cracks were produced by placing the concrete prisms on steel bars and applying a pressure on the opposite side of approximately 6-7 tons. The time taken to finalize the first measurement (without cracks) and to initiate the second measurement (with cracks) was limited to a 48-hour time span.

Before the initial radon measurement of each prism, the prism was sealed with aluminum tape as to ensure only radon from the surface would be exhaled. After radon measurement of the prism, in its pristine state, the concrete prism was partially dismantled from its aluminum tape and brought to the pressure press. Three cracks were induced. Thereafter all the aluminum tape was stripped off. Measurements of the cracks' length and width were recorded. Thereafter, the concrete prism was once again sealed with aluminum tape, except from the top. Thereafter radon measurement was initiated once again. After finalized measurement, the concrete prism was brought back to rest within its plastic box and the next concrete prism trials were initiated.

The produced cracks were in all cases brittle in their characteristics (Figure $4 \mathrm{~b}$ ). The cracks arose with a clear "bang", and the possibility to control the aperture/width of the cracks were not achievable. Thus, the induced/produced cracks were after "failure" measured from side to side (Figures $4 \mathrm{c}$ and $4 \mathrm{~d}$ ), and the width of the cracks were accepted as they appeared. The reinforcement by steel fibers seemingly confined the spread of the cracks. In Figure 5a, the procedure of inducing/producing the cracks is shown. Three cracks were produced in each prism. In almost all cases, the cracks continued through the prisms until less than $10-15 \mathrm{~mm}$ of the concrete remained. In only two cases, the cracks could be noted/observed on the opposite side of the concrete prisms. 


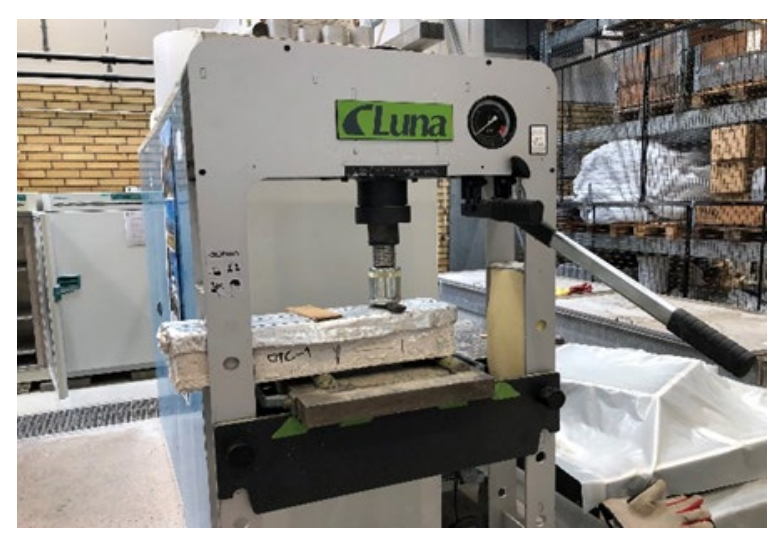

(a) Luna pressure press used to induce cracks in concrete prisms

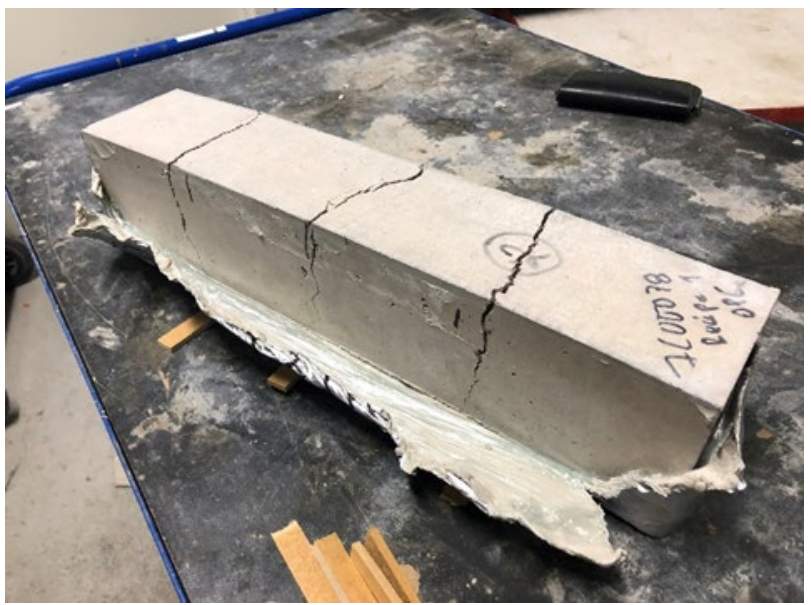

(c) Concrete prism resting on a carriage. The induced cracks are noticeable on top and alongside of the concrete prisms. The prism is REF 1-2.

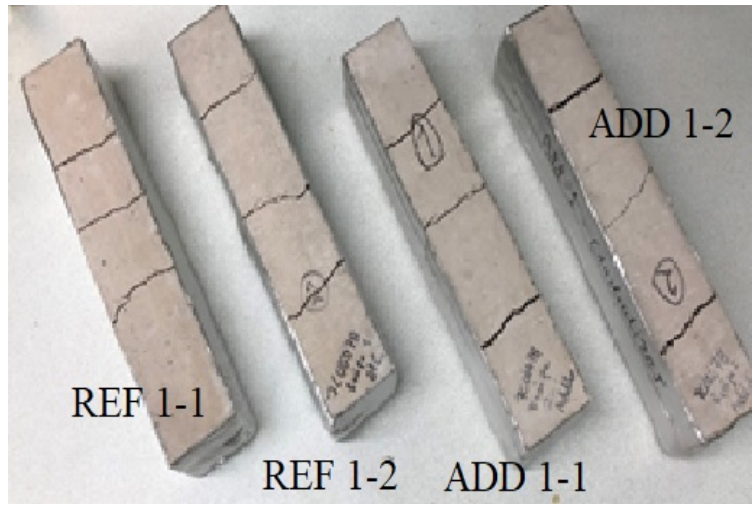

(b) The concrete prism after finalized measurements, with cracks produced. Note the larger width from the cracks on the prisms from recipe " $A D D$ "

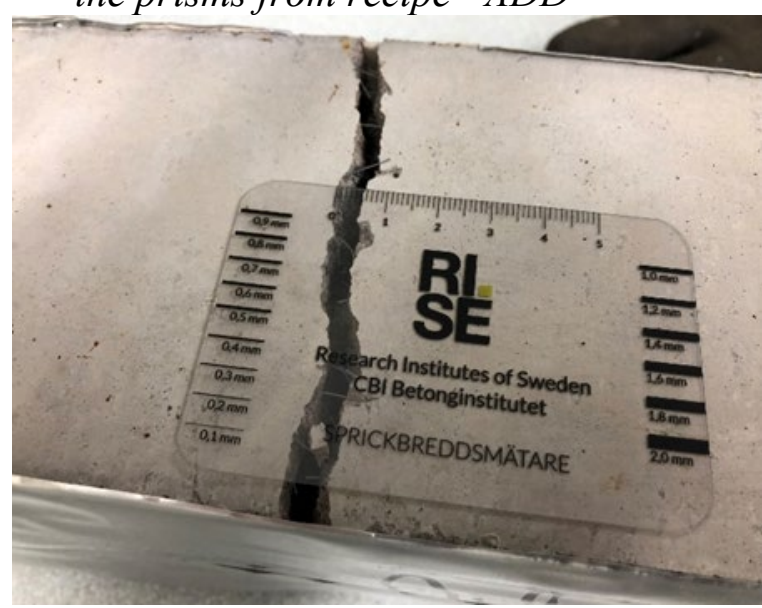

(d) The aperture of the crack measured. The aperture is ca $4.5 \mathrm{~mm}$. Prism ADD 1-2.

Figure 4 - The procedure of introducing cracks in the prisms.

\subsection{Measurements of radon gas and radon exhalation rate}

The principle makes use of a "closed system with a radon sample enclosed". As radon from the concrete product builds up within a sealed aluminium container (Figure 5a, b) a measure of the radon exhalation rate could be calculated for the first 24 hours. The codes adopted are defined in ISO Standard 11665-7 [5].

The radon gas exhalation rate $E\left(\left(\mathrm{~Bq} / \mathrm{m}^{2}\right) / \mathrm{h}\right)$ is calculated knowing the initial conditions of the radon gas concentration in a "closed system" and within this project the linear regression model has been applied. The equation for the linear regression model can be described as: 


$$
E=\left\{\left(C-C_{0}\right) \times V\right\} /(A \times t)
$$

where: $E=$ exhalation rate of radon gas $\left(\left(\mathrm{Bq} / \mathrm{m}^{2}\right) / \mathrm{h}\right), C=$ concentration of radon gas measured by the radon gas monitor $\left(\mathrm{Bq} / \mathrm{m}^{3}\right), C_{0}=$ background concentration of radon gas at initiation $\left(\mathrm{Bq} / \mathrm{m}^{3}\right)$, $t=$ time of duration (h), $A=$ effective surface area of the sample $\left(\mathrm{m}^{2}\right), V=$ volume of the container including hoses $\left(\mathrm{m}^{3}\right)$.

The Swedish Cement and Concrete Institute uses an ATMOS 33 semiconductor equipment developed by Gammadata $\mathrm{AB}$ (Figure 5a). The instrument uses an ionizing pulsation chamber that measures the alpha decay of ${ }^{218} \mathrm{Po}$. The decay of ${ }^{\mathbf{2 1 8}} \mathrm{Po}$ has a distinct electric charge of $6 \mathrm{MeV}$ that could be counted and converted to ${ }^{222} \mathrm{Rn}$ knowing the decay rates of ${ }^{222} \mathrm{Rn}$ and ${ }^{218} \mathrm{Po}$.

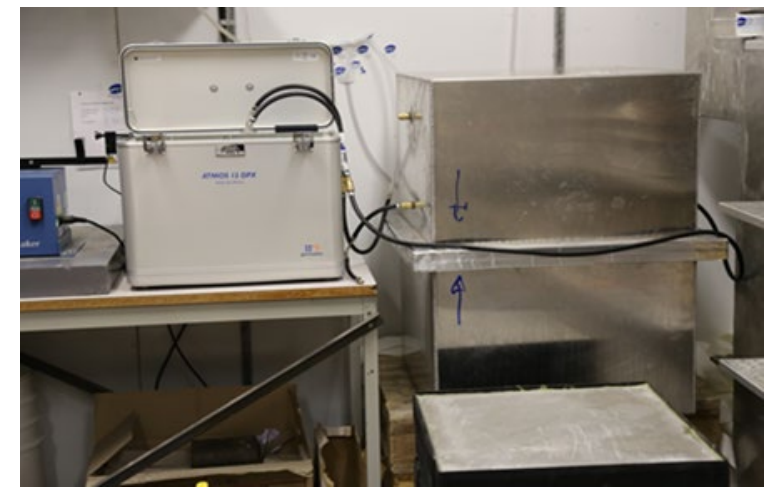

(a)

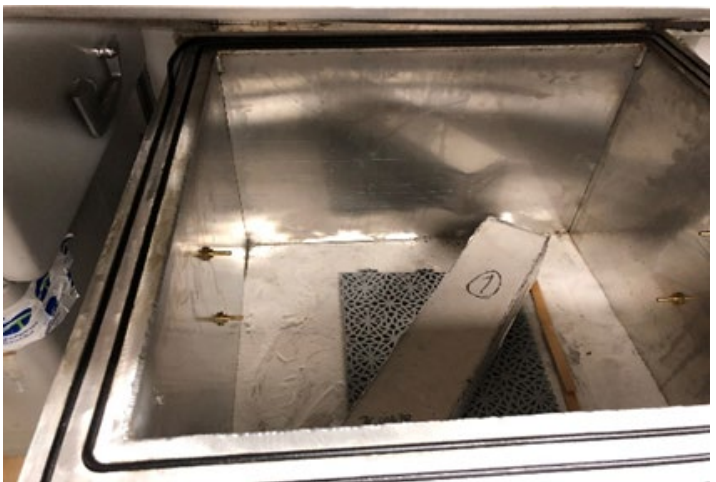

(b)

Figure 5 - (a) The Atmos 33 (Atmos 12DPX) connected to the aluminium container. The sealing of the containers is made with a butyl-aluminium tape that has been tested to ensure no leakage of radon. (b) The container with the REF-concrete prism resting on the bottom of the open container.

3.

RESULTS

\subsection{Compressive strength}

The compressive strength was examined in order to verify the quality of the concrete recipes (Table 2). The compressive strength was performed on cubes from each recipe in size $100 \times 100 \times 100$ $\mathrm{mm}$. The concrete cubes had been stored in the same environment as the prisms. The strength was controlled after 28 days and when the first initial measurements commenced for radon, roughly one year from casting. Table 2 presents the results.

Table 2 - Results of the compressive strength for each recipe.

\begin{tabular}{lcc}
\hline Recipe & \multicolumn{2}{c}{ Compressive strength (MPa) } \\
& 28 days & 365 days \\
\hline REF & 65 & 82 \\
ADD & 50 & 69 \\
\hline
\end{tabular}


An approximate calculation of the total surface area increase due to the cracks propagation in the concrete prisms were made from measurements of each crack (Fig. 1, Fig. 4c, d). The cracks were noted on each side of the prisms by ocular inspection. Thereafter a planar surface increase due to the crack's extension could be calculated. Thus, an approximate estimate of the total surface (Table 3) including newly exposed concrete surface due to produced cracks as well as initial surface defined as top surface of the concrete prism could be estimated. From the tabulated data (Table 3) one can observe that the total surface due to the initiated cracks has more than doubled the total surface where radon can escape into the air. Also, a mean width/aperture of the induced cracks, at the top surface, was calculated for each concrete prism (Figure 4d). The measured mean width/aperture of each crack was added together to give an overall mean width/aperture (Table 3) for each prism.

Table 3 -Estimated surface increase due to fractures induced and measured mean width/aperture of cracks for each concrete prism.

\begin{tabular}{cccccc}
\hline $\begin{array}{c}\text { Concrete } \\
\text { prism }\end{array}$ & $\begin{array}{c}\text { Top surface } \\
\text { (initial } \\
\text { surface) } \\
\left(\mathrm{m}^{2}\right)\end{array}$ & $\begin{array}{c}\text { Surface } \\
\text { increase due } \\
\text { to fractures } \\
\left(\mathrm{m}^{2}\right)\end{array}$ & $\begin{array}{c}\text { Total } \\
\text { surface } \\
\left(\mathrm{m}^{2}\right)\end{array}$ & $\begin{array}{c}\text { Surface } \\
\text { magnification } \\
\text { factor }\end{array}$ & $\begin{array}{c}\text { Mean } \\
\text { width/aperture } \\
\text { of cracks at the } \\
\text { surface } \\
(\mathrm{mm})\end{array}$ \\
\hline REF 1-1 & 0.050 & 0.054 & 0.104 & 2.08 & 1.6 \\
REF 1-2 & 0.050 & 0.053 & 0.103 & 2.06 & 1.6 \\
ADD 1-1 & 0.050 & 0.057 & 0.107 & 2.14 & 2.8 \\
ADD 1-2 & 0.050 & 0.058 & 0.108 & 2.15 & 3.4 \\
\hline
\end{tabular}

\section{3}

\section{Radon gas measurements}

Table 4 presents the calculated results of the radon exhalation measurements. The table presents the data as the radon exhalation rate $\left(\left(\mathrm{Bq} / \mathrm{m}^{2}\right) / \mathrm{h}\right)$ before the cracks were initiated (pristine state) compared to a measurement when the cracks were initiated. For the concrete recipe of ordinary Portland cement, named REF 1-1 and REF 1-2, an increase between 80 and $120 \%$ were calculated. For the second concrete recipe, named ADD 1-1 and ADD 1-2, an increase between 200 and $260 \%$ were calculated.

Table 4 - Results of the radon exhalation measurements of each prism in a pristine state and after cracks were induced.

\begin{tabular}{lcccccccc}
\hline Prisms & \multicolumn{2}{c}{ REF 1-1 } & \multicolumn{2}{c}{ REF 1-2 } & \multicolumn{2}{c}{ ADD 1-1 } & \multicolumn{2}{c}{ ADD 1-2 } \\
& Prist. & Cracks & Prist. & Cracks & Prist. & Cracks & Prist. & Cracks \\
\hline $\begin{array}{l}\text { Exhalation } \\
\text { rate }\end{array}$ & 38.2 & 67.3 & 36.1 & 78.6 & 31.9 & 114.6 & 26.3 & 79.5 \\
$\begin{array}{l}\left.\left(\mathrm{Bq} / \mathrm{m}^{2}\right) / \mathrm{h}\right) \\
\begin{array}{l}\text { Magnification } \\
\text { factor }\end{array}\end{array}$ & $(1)$ & 1.8 & $(1)$ & 2.2 & $(1)$ & 3.6 & $(1)$ & 3.0 \\
$\begin{array}{l}\text { Difference } \\
(\%)\end{array}$ & & 76 & & 118 & & 259 & & 202 \\
\hline
\end{tabular}


The compressive strength of the examined concrete cubes is in line with expectations or possibly better [10]). The results seem solid and a lower compressive strength for a recipe containing a hydrophobic additive is anticipated [6]. This is also, what could be observed from the results.

The crack distribution/propagation and width of cracks were factors not easily controlled. Use of fibres were successful in hindering a crack propagation trough the prisms but also to "lock" the produced crack in position after being produced. In a few cases, also minor cracks could be noticed partly perpendicular to the main crack direction. These minor cracks are overlooked in the approximated calculations of the increased total surface (Table 3). However, these minor cracks may play a significant role in the overall crack distribution, within the concrete prisms, and as such their contribution to the total surface exposure. Secondly, the width/aperture of cracks when induced/produced were markedly larger for the recipe "ADD". These larger cracks occurred for both prisms (ADD 1-1 and ADD 1-2) exerted to the pressure press. The largest cracks measured approximately $4-5 \mathrm{~mm}$ in width. The reason for this is not clear but indicates a possible more brittle failure than for the reference concrete (REF). The observered brittle failure may also internally have produced a larger number of minor cracks not recognised at the surface.

The results indicate a clear increase of the radon exhalation rate, nonetheless of concrete recipe examined. For the "REF recipe" an increase between 80 and $120 \%$ is calculated. This is partly in line, with the calculated total surface exposure increase (Table 2). For the recipe "ADD" an increase between 200 and $260 \%$ in radon exhalation rate was calculated. This is more than anticipated, and the explanations may be linked to the obvious large crack widths/apertures produced. Moreover, the possibly more brittle failure, may also have produced more internal cracks not recognized from the ocular inspection. A third explanation may lie in the fact that more aggregates by coincidence were accessible along the surface in comparison to the recipe of "REF". In this study, the aggregates are likely those that contribute the most to the radon production [9]. It should be recognised that the induced fractures in part, makes aggregates accessible at the surface of the concrete. In the pristine tests, there is initially a layer of cement paste. It is reasonable to believe that aggregates along the surface in combination with cement paste (as is the case when fractures have occurred) will generate a slightly higher radon exhalation rate, due to the fact that the aggregates are directly able to exhale radon into the air. Thus, it would be of interest to further explore a cast concrete surface, where the conditions are exactly equal in the pristine state as well as after cracks have been induced. But in this study, an approach, simulating an in part realistic condition, e.g. a cracked floor, has been adopted.

Moreover, it should be pointed out, that the calculations in this study with regard to the surface areas when they are related to cracked surfaces, have been calculated as "an even surface". However, this is not entirely a correct approach. A slight increase of the cracked surface areas, due to uneven cracking (and thus uneven surfaces) is obviously a more accurate approach. But, in this study, the effect of an uneven surface, and how much the surface area increases due to this, has been neglected. However, this is recommended to further elaborate upon with accuracy in future research within this topic.

Finally, it should be noted that the initial radon exhalation values measured for the exhalation rate of the concrete prisms in a pristine state, is lower for the recipe "ADD". This is as predicted [6], but a small change in these lower values have a large impact, when a percentage increase is calculated. 


\section{5.}

\section{CONCLUDING REMARKS}

In the current study it has been demonstrated a strong influence upon the radon exhalation rate, by inducing cracks in concrete prisms. The rate of radon exhalation is markedly higher compared to when the exhalation rate from only the top surface of the concrete is calculated.

An increase in the mean width/aperture of the concrete prisms seemingly correlates with an increase in the radon exhalation rate.

The increase of radon gas is remarkable for one of the recipes. One probable cause can be several minor cracks, not noticeable at the surface and being caused when load was exerted by the pressure press to induce cracks.

The study has shown that the radon exhalation rate is strongly affected by cracks in concrete. This serves as a reminder of not striving to produce floors and walls, with only the economical aspect in mind, where too slender concrete structures, may easily break, produce cracks in the concrete and subsequently generate secondary effects such as a strong increase in radon gas production.

The hypothesis seemingly has a good correlation for one of the recipes (REF), where the mean aperture/width was less than $2 \mathrm{~mm}$. But it is apparent that the aperture/width may play a significant role in the final exhalation rate regarding the results of the recipe including an additive.

Further research in the area is needed, e.g. a more detailed study of how the fractures were distributed within the concrete after the pressure press had induced the cracks would have been of most importance. However, this was beyond the scope of this study. But further documentation of crack propagation within concrete and its effect on the exhalation rate are recommended and should be promoted to gain a better understanding of what could be expected when cracks appear in concrete and what effects that may give on the final exhalation rate of radon.

\section{6.}

\section{ACKNOWLEDGEMENTS}

Special thanks to the Swedish Consortium for Financing Fundamental Research in the Concrete Area who has partly funded the research in the concrete area. Special thanks also to the first author's supervising group and his colleagues at RISE CBI aiding with some tests.

\section{REFERENCES}

1. World Health Organization: "WHO Handbook on Indoor Radon: a Public Health Perspective". World Health Organization, Geneva, Switzerland, 2009, 110 pp.

2. Man C K \& Yeung H S: "The Effects of Cracks and Holes on the Exhalation of Radon from Concrete". Building and Environment, Vol 32, No. 4, 1997, pp. 351-354.

3. Landman K A: "Diffusion of Radon Through Cracks in Concrete Slab". Health Physics, Vol. 43, Issue 1, 1982, pp. 65-71.

4. Ajayi K M, Shahbazi K, Tukkaraja P, Katzenstein P: "A discrete model for prediction of radon flux from fractured rocks", Journal of Rock Mechanics and Geotechnical Engineering, 10, 2018, pp. 879-892 
Nordic Concrete Research - Publ. No. NCR 61 - ISSUE 2 / 2019 - Article 5, pp. 79-90

5. ISO 11665-7. "Measurement of Radioactivity in the Environment - Air: Radon-222 Part 7: Accumulation Method for Estimating Surface Exhalation Rate". International Standard (ISO), First edition, Geneva, Switzerland, 2012, 23 pp.

6. Döse M \& Silfwerbrand J: "Reduction of radon gas in concrete using admixtures and additives", Nordic Concrete Research, Vol. 58, 2018, pp. 17-34.

7. Cozmuta I \& van der Graaf E R: "Methods for Measuring Diffusion Coefficients of Radon in Building Materials". The Science OF THE Total Environment, Vol. 272, 2001, pp. 323335.

8. Fournier F, Groetz J E, Jacob F, Crolet J M \& Lettner H: "Simulation of Radon Transport through Building Materials: Influence of the Water Content on Radon Exhalation Rate". Transport in Porous Media, Vol. 59, 2005, pp. 197-214.

9. Döse M: "Ionizing Radiation in Concrete and Concrete Buildings - Empirical Assessment". Bulletin No. 141 (Licentiate Thesis), KTH Royal Institute of Technology, School of Architecture and Built Environment, Dept. of Civil \& Architectural Engineering, Chair of Concrete Structures, Stockholm, Sweden, 2016, 91 pp.

10. Neville A M \& Brooks J J: “Concrete Technology”. $2^{\text {nd }}$ Edition, Prentice Hall, Harlow, Great Britain, 2010, 442 pp. 